\title{
Accountability e Gestão Pública: possibilidades e limites da participação no aperfeiçoamento das políticas públicas
}

\author{
Jeferson Batista Silva ${ }^{1}$
}

\begin{abstract}
RESUMO
O objetivo deste artigo é discutir se os mecanismos de accountability, foco no controle social, são realmente efetivos na qualificação das políticas públicas. Em nenhum outro momento abordou-se tanto a importância de se criar mecanismos de controle do poder público. No entanto, considera-se que boa parte destas discussões não consegue transpor barreiras da cultura organizacional da administração pública e ser efetivamente realizada. A relevância deste tema reside no fato de que nos discursos se propaga a importância do controle social na definição, monitoramento e avaliação das políticas públicas. No entanto, este discurso não consegue se materializar em práticas efetivas, e muitas vezes o que se observa é a coexistência de um discurso moderno com práticas tradicionais. Discutir esta temática torna-se então fundamental para a compreensão e elaboração de mecanismo para superar esta distância entre discurso e prática. Para a construção deste artigo foi utilizada a metodologia da pesquisa bibliográfica, com a leitura de autores especializados na temática abordada, como Campos (1990) e O'Donnel (1998). Conclui-se que a edição das leis e um discurso formal sobre a importância da accountability e do controle social não são fatores suficientes para alterar um padrão de cultura da administração pública. Para a superação desta cultura, torna-se fundamental a consolidação dos princípios da democracia e a ampliação dos mecanismos de participação.
\end{abstract}

Palavras-chave: Administração pública; Accountability; Controle social.

\section{Accountability and public Management: possibilities and limits of participation in the improvement of public policies}

\begin{abstract}
The purpose of this article is to discuss whether accountability mechanisms, focus on social control, are really effective in the qualification of public policy. At no other time is approached both the importance of creating mechanisms of control of public authorities. However, it is considered that many of these discussions can not overcome barriers of organizational culture of public administration and be effectively performed. The importance of this matter lies in the fact that in the reports propagates the importance of social control in defining, monitoring and evaluation of public policies. However, this speech fails to materialize into effective practices, and often what is observed is the coexistence of a modern discourse with traditional practices. Discuss this issue then becomes fundamental to understanding and developing mechanism to overcome this distance between discourse and practice. For the construction of this article we used the methodology of literature, by reading expert authors in the subject addressed as Fields (1990) and O'Donnell (1998). It is concluded that the issue of laws and a formal speech on the importance of accountability and social control are not enough factors to change a pattern of culture of public administration. To overcome this culture, it is essential to consolidate the principles of democracy and the expansion of participation mechanisms.
\end{abstract}

Keywords: Public administration; Accountability; Social control.

\section{INTRODUÇÃO}

A administração pública, segundo Matias-Pereira (2010) e Sanabio, Santos, David (2013), seria, em um sentido mais amplo, as estruturas (serviços e entidades) do poder

\footnotetext{
${ }^{1}$ Psicólogo. Cientista Político. Especialista em Gestão Pública. Mestre em Gestão Social e Desenvolvimento (UNA).
} Email: jefersonbatis@yahoo.com.br 
público, incumbidas da missão de concretizar as decisões políticas e legislativas, com o objetivo de gerar um bem comum à sociedade. A administração pública no mundo e no Brasil se apresenta como um processo constante de mudanças e aperfeiçoamentos.

Ao longo da história, a administração pública passou por três momentos muito característicos: o período patrimonialista, o período burocrático e o período gerencial. Este processo é reflexo da própria evolução da organização dos Estados nações, bem como do crescimento econômico mundial. Partiu-se de uma estruturação do poder público que girava em torno do rei e de suas decisões (período patrimonialista), passando por uma organização estatal baseada em modelos e em processos (período burocrático) até chegar aos conceitos atuais de avaliação por resultados, governança, accoutability e controle social (período gerencial). (COSTIN, 2010; MATIAS-PEREIRA, 2010; OLIVEIRA, 2014; PALUDO, 2016). A implementação do modelo de administração pública gerencial iniciou-se no final da década de 1970, com grande repercussão mundial na década de 1980. Teve como objetivo a busca de padrões da administração privada e sua aplicação na gestão pública. Trata-se de um período de dificuldades econômicas em todo o mundo, em que era preciso melhorar a aplicação das verbas públicas, "fazer mais com menos". Entre vários pontos desta transposição do setor privado ao setor público destacam-se os conceitos de governança e os modelos de prestação de contas do poder público accountability. (COSTIN, 2010; MATIAS-PEREIRA, 2010; OLIVEIRA, 2014; PALUDO, 2016).

Esta transição de conceitos e de formas de trabalho marcam também a busca de uma nova forma de relação com a população, que requer uma maior participação dos usuários na definição das políticas públicas, na fiscalização de sua implementação e nos resultados obtidos. O Estado e seus representantes deixam de planejar e definir as políticas públicas de forma isolada e passam a ter que discutir o planejamento, a implementação das políticas públicas e a prestar contas de suas ações ao público ou a representantes destes, eleitos em assembleias $^{2}$.

No entanto, a criação destes mecanismos e espaços de participação não é suficiente para mudar décadas de uma cultura de trabalho dentro da gestão pública mundial e brasileira. A partir desta constatação, questiona-se se o controle social é um efetivo fator de qualificação das políticas públicas, ou seja, a criação dos espaços e mecanismos de accountability, transformando a administração pública, qualificando suas ações através das

\footnotetext{
${ }^{2}$ Como são eleitos por exemplos os conselheiros municipais, estaduais e federais de saúde, cuja principal função e monitorar o planejamento, a execução e acompanhar as prestações de conta das respectivas secretarias de saúde e do Ministério de Saúde.
} 
políticas públicas. Esta questão norteou o objetivo central do presente artigo, que buscou, na pesquisa bibliográfica, por meio de levantamento em livros e artigos científicos respostas para tal questionamento. A hipótese é de que há muito para se fazer até que os mecanismos de accountability, em especial o controle social, efetivamente consigam gerar mudanças na gestão pública, para além de mudanças estéticas, e produzam resultados que alterem a forma de funcionamento do poder público.

Este artigo inicia-se com uma breve introdução, onde o tema de pesquisa é apresentado, bem como sua importância, o problema a ser estudado e o propósito. Posteriormente, destaca breve apresentação sobre administração pública e expõe acerca do processo de evolução da administração pública em nível mundial; em seguida, explana sobre a evolução da administração pública no Brasil seguindo as influências mundiais e discute a relação entre administração pública, accountability e controle social e, por fim, realiza a discussão sobre a efetividade dos mecanismos de controle social nas políticas públicas. E, por último, estão colocadas as conclusões e contribuições sugeridas.

\section{ADMINISTRAÇÃO PÚBLICA: ALGUMAS CONCEPÇÕES}

A organização do poder público, ao longo dos séculos, transformou-se a partir das mudanças na compreensão do papel dos cidadãos de uma dada nação, ou seja, da ampliação do conceito de cidadania. Observa-se uma transição da concepção de súditos, detentores de um único "direito", o de servir ao seu senhor, para a moderna concepção de cidadãos, detentores de múltiplos direitos como civis, de expressão, etc. Em decorrência desta ampliação do conceito de cidadania observam-se também, mudanças na própria concepção e nos objetivos do Estado. Desta forma, a administração pública se constitui enquanto uma administração patrimonialista atravessa um período onde é considerada uma administração burocrática até se tornar uma administração gerencial, no presente século. Mas o que seria enfim administração pública e em que se baseiam estas diferenciações inicialmente apresentadas?

Segundo Matias-Pereira (2010) e Sanabio, Santos, David (2013), a administração pública seria a forma de organização do poder público que se institui em entidades e serviços com vistas nas atividades administrativas, ou seja, a execução das decisões políticas e legislativas. Acrescenta-se que esta organização se estrutura em um determinado território, e este território define a abrangência das determinações a serem realizadas. Toma-se como 
exemplo a atuação de um poder público municipal: suas decisões políticas e legislativas terão validade em seu território. Este mesmo princípio de abrangência se aplica aos estados ou províncias ou outras formas de subdivisão nacional, onde estas existirem, e aos países.

A cidadania, por sua vez, relaciona-se a um conjunto de direitos e deveres que um cidadão possui. Não se trata de algo natural e sim socialmente conquistado, pois os direitos são conquistados por meio da organização e pelas lutas sociais. A sociedade civil, ou seja, os membros organizados de uma determinada população buscam espaços instituídos ou os instituem com o objetivo de se fazerem ouvir e influenciar nos processos decisórios da administração pública.

\footnotetext{
Os conceitos de sociedade civil e de esfera pública constituem o eixo central da democracia deliberativa. O caráter associativista, autônomo e crítico das organizações da sociedade civil impõe a esta esfera uma legitimidade da apresentação, problematização e representação de demandas e interesses sociais. O caráter dialógico, reflexivo, participativo e tensionador da esfera pública confere uma mudança na natureza dos processos decisórios, deslocando-os dos espaços fechados e restritos do poder tradicional para os espaços abertos e iluminados da participação social (LUCHMANN, 2002, p. 67).
}

Nota-se, ao longo da história, processos pendulares relacionados à participação e à capacidade de intervenção e direcionamento da população com relação às ações do poder público. Estes avanços e retrocessos marcam a trajetória histórica de organização da administração pública.

No processo de constituição das nações e de suas estruturas burocráticas, observam-se muitas mudanças nas visões políticas e nas posturas da população. Tais fatores foram marcantes nos grandes momentos da administração pública. Para melhor compreensão do tema deste artigo, faz-se necessário uma apresentação destes momentos e das principais características da organização da administração pública nestes períodos.

\section{A TRAJETÓRIA DA ADMINISTRAÇÃo PÚBLICA NO ÂMBITO MUNDIAL}

O nascimento das modernas nações é marcado pelo processo de consolidação do poder real sobre um determinado território. Historicamente, trata-se da superação do feudalismo e surgimento e fortalecimento do capitalismo. Os burgueses necessitavam de uma estrutura organizacional que favorecesse o comércio e para tanto era necessária uma organização burocrática nos territórios, como leis, moeda, critérios de pesos e medidas, 
segurança e vias de acesso. Cabia ao rei a formulação de todos estes parâmetros burocráticos do Estado nação, daí a concepção de Estado absolutista. Não havia neste momento diferenciação entre os bens do rei e da nação, já que a nação e suas posses pertenciam ao rei. Assim, o Estado pertencia ao rei, sendo este quem indicava a classe burocrática. Neste contexto,

O aparelho de Estado atua como uma extensão do poder do monarca. Os servidores públicos possuem status de nobreza real. Os cargos funcionam como recompensas, o que gera nepotismo. Isso contribui para a prática de corrupção e do controle do órgão público por parte dos soberanos (MATIAS-PEREIRA, 2010, p. 113).

Novamente observa-se o papel de destaque da classe burguesa no avanço social e político. O comércio precisa de um ambiente de estabilidade e clareza para se desenvolver. $\mathrm{O}$ nascimento das modernas nações e o fortalecimento do poder real consolidaram este ambiente propício ao desenvolvimento comercial. Contudo, o avanço das práticas comerciais não era condizente com o excesso de intervenção do poder real nas práticas comerciais. Foi necessária uma mudança na lógica de estruturação do sistema, o que fez com que a burguesia buscasse seu reconhecimento como classe detentora do poder.

Ocorre a transição do período de monarquias absolutas para monarquias democráticas ou repúblicas. Uma mudança de grande magnitude que impactou diretamente na estruturação da administração pública, levando à transição da administração patrimonialista para a administração burocrática.

A administração pública burocrática nasce na segunda metade do século XIX, com o objetivo de combater a corrupção e o nepotismo patrimonialista. Pregava os princípios do desenvolvimento, da profissionalização, ideia de carreira pública, hierarquia funcional, impessoalidade, formalismo tudo cominava no poder legal, colocando a priori as metas de acabar com o nepotismo e com a corrupção (MATIAS-PEREIRA, 2010, p. 113).

Destaca-se na consolidação da administração pública burocrática o arcabouço teórico desenvolvido pelo sociólogo alemão Max Weber³

\begin{abstract}
Adoção do princípio hierárquico nas organizações, baseada em 'um sistema firmemente ordenado de super e subordinação, no qual há supervisão dos níveis inferiores de funcionários pelos níveis superiores'; a lealdade impessoal devotada a postos funcionais hierarquicamente superiores; a eficiência como resultante da implementação impessoal de regras racionais e impessoais, desde que não haja interferência política (WEBER, 2004, p. 144).
\end{abstract}

\footnotetext{
${ }^{3}$ Sociólogo alemão considerado um dos fundadores da moderna Ciências Sociais, destacou-se nos estudos sobre a estruturação do poder público.
} 
A institucionalização da administração pública burocrática representou em todo o mundo um grande avanço na qualidade dos serviços públicos, estabelecendo o conceito de meritocracia no serviço público e as condições do estado liberal necessárias ao pleno desenvolvimento comercial e industrial. Acontece que o conceito de estado liberal refere-se a um Estado que proporciona um conjunto mínimo de ações do poder público à sua população. Este conjunto refere-se a questões de segurança, à propriedade, aos meios de circulação física e à liberdade de negócios. Na realidade, este Estado beneficia a classe detentora dos meios de produção econômicos. Este mínimo não se relaciona ao conjunto de políticas de cunho social. (COSTIN, 2010; MATIAS-PEREIRA, 2010; OLIVEIRA, 2014; PALUDO, 2016).

Esse é um período de grande geração de riquezas e produção de exclusão, em que se observa o surgimento de vários movimentos de cunho reivindicativo: sindicalismo, anarquismo, socialismo. Frente a esta movimentação, as classes detentoras do poder instalam um processo de cessão de benefícios sociais e trabalhistas às classes menos favorecidas, de forma a manter a estabilidade política e social. Trata-se de ações ainda limitadas, mas já criando um sistema de proteção ao trabalhador. (COSTIN, 2010; MATIAS-PEREIRA, 2010; OLIVEIRA, 2014; PALUDO, 2016).

Em 1929, todo o mundo capitalista é abatido pela quebra da bolsa de Nova York, instalando-se a maior crise econômica e social da história da humanidade. O mundo somente superará esta crise a partir da aplicação dos pressupostos do Welfare State (Estado de bemestar social). As políticas de proteção social são fortemente ampliadas, o Estado passa a investir e intervir diretamente no mercado. Novas ações são solicitadas ao estado burocrático e cada vez este se torna mais complexo, intervindo em vários campos, indo para além da própria estrutura do Estado. (COSTIN, 2010; MATIAS-PEREIRA, 2010; OLIVEIRA, 2014; PALUDO, 2016).

No entanto, ao longo da história, novas mudanças ocorrerão na realidade mundial. Superada a crise de 1929, uma nova grande guerra mundial (1939-1945) se abaterá sobre a humanidade e só terá fim em 1945. Ao final da segunda guerra mundial, o mundo vivenciará um período de grande avanço econômico e social. Trata-se de uma "época de ouro para o capitalismo" e para o fortalecimento do Estado de bem-estar social, um período de geração de grandes riquezas e expansão do modo de produção capitalista. Os países considerados periféricos também se beneficiarão deste momento, especialmente financiados pelo grande 
volume de crédito disponível em todo o mundo. (COSTIN, 2010; MATIAS-PEREIRA, 2010; OLIVEIRA, 2014; PALUDO, 2016).

No início da década de 1970, o modelo de crescimento econômico baseado no crédito externo farto se esgotou. $\mathrm{O}$ mundo vivencia a primeira crise do petróleo, as economias enfrentam uma crise de retração econômica, as taxas de crescimento caem significativamente, o que ocasionará três grandes impactos na administração pública burocrática: a crise fiscal do Estado, a retração econômica e, por consequência, o aumento de déficits nos orçamentos governamentais. Estes, não tendo mais como se financiar em longo prazo com empréstimos externos, são obrigados a elevar impostos sem manter a qualidade dos serviços públicos, o que culmina em uma crise de governabilidade. A população observa sua qualidade de vida regredir e não vê o poder público como capaz de, efetivamente, reverter este quadro. Acrescenta-se a isto a emergência da globalização e das inovações tecnológicas, que diminuiu significativamente a capacidade do Estado em desenvolver e administrar sua política macroeconômica. (COSTIN, 2010; MATIAS-PEREIRA, 2010; OLIVEIRA, 2014; PALUDO, 2016).

É neste contexto que surge a administração pública gerencial que tenta readequar o Estado às grandes mudanças ocorridas na década de 1970. Busca-se, na administração privada, inovações que possam qualificar a atuação da administração pública, potencializando o agora escasso recurso financeiro. Introduz-se a ideia de eficiência na atuação do Estado, após anos de gastos equivocados. Com maior ou menor ênfase, observa-se em todo o mundo capitalista a adoção da administração pública gerencial e a adequação do poder público frente a esta nova realidade. No Brasil, tal fato será ainda mais agravante, considerando ser o país um membro periférico da ordem capitalista que vivencia um processo de transição de uma ditadura militar para um governo democrático. (MATIAS-PEREIRA, 2010; SANABIO, SANTOS e DAVID, 2013).

\section{A TRAJETÓRIA DA ADMINISTRAÇÃO PÚBLICA NO BRASIL}

Ao longo de sua trajetória como nação, a atuação do poder público brasileiro sofreu influência das ideias e das visões externas de qual seria o papel do Estado. Cabe aqui destacar que a administração pública brasileira não se apresenta estanque, muito pelo contrário, ela se mostra em constante atualização, constante aperfeiçoamento. No entanto, 
características culturais e a própria estruturação do Estado brasileiro ainda são fatores marcantes na atuação do poder público, por meio de seus órgãos e profissionais.

A trajetória da Administração Pública no mundo e no Brasil é marcada por três fases distintas, como apresentadas anteriormente: administração pública patrimonialista, administração pública burocrática e administração pública gerencial. Estes três momentos se apresentam de forma clara na trajetória histórica do Estado brasileiro. Durante a monarquia brasileira, a administração pública nacional era muito precária, sendo baixa sua estruturação e não havia uma separação entre o patrimônio real e público. As ocupações de cargos públicos se davam por indicações, e o objetivo era ocupar nobres em cargos de destaque e seus afilhados políticos ${ }^{4}$ em cargos de menor importância. Como já relatado, tal fato ocasionava baixa qualidade das ações do servidor público, bem como altos índices de corrupção. (MATIAS-PEREIRA, 2010; SANABIO, SANTOS e DAVID, 2013).

Em 1889 ocorre a proclamação da república. Há um ideal de emancipação do Brasil e a busca pelo aperfeiçoamento da administração pública. No entanto, não se observa grandes diferenciações com relação ao trato da "coisa pública", ou seja, a estrutura do Estado. Durante a república velha permanece a administração patrimonialista do Estado, e os coronéis ${ }^{5}$ continuam demonstrando seu poder no uso do Estado por meio de indicações de seus apadrinhados aos cargos públicos. Tal ação demonstrava uma clara posição de poder e garantia a atuação do poder público (do Estado) em favor dos grandes proprietários rurais e seus próximos.

Em 1930, o Brasil vivencia uma revolução, a chamada “Revolução de 30”. Não se trata aqui de uma revolução popular, mas sim de uma revolução realizada por grupos de interesses discordantes dos grupos dominantes de Minas Gerais e São Paulo. Essa revolução marca o fim da primeira república brasileira, o fim da república velha, e inicia-se o período “Getulista”, que somente se encerrará em 1945. Este período é marcado pelo processo de industrialização nacional com forte caráter de intervenção estatal, em que o governo busca um processo de crescimento econômico e, para tal, precisará de uma estrutura forte capaz de conduzir este processo.

\footnotetext{
${ }^{4}$ A expressão "apadrinhados políticos" remete-se ao fato cultural e religioso (Igreja Católica) de se escolher um padrinho para o batizado de um filho. Cabe aos padrinhos serem "os segundos pais e mães" do afilhado. Tornouse comum escolher pessoas de um nível social acima da classe social da família, de forma a propiciar a possibilidade de indicações através do padrinho.

5 A expressão "coronéis" vem do título militar de Coronel da Guarda Nacional que era dado a grandes proprietários de terras durante o período imperial, onde esta guarda teve papel de destaque na defesa do território brasileiro.
} 
A administração pública brasileira assume um caráter burocrático segundo os modernos referenciais da época. É criado o Departamento de Administração do Serviço Público - DASP, em 1936. A busca pela industrialização nacional se dá pela forte intervenção do Estado e para tal é necessária uma ampliação das ações do poder público. Trata-se de um período de grande ampliação das estruturas do Estado e da busca de racionalização de sua atuação. Introduz-se neste momento a meritocracia no poder público, em que os ocupantes de cargos do serviço público passam a ser selecionados por concurso público e há um conjunto claro de ações a serem executados por cada profissional. (MATIAS-PEREIRA, 2010; SANABIO, SANTOS e DAVID, 2013).

Embora seja possível creditar ao período de governo de Getúlio Vargas (1930 1945) um grande avanço nacional, nos chama atenção para o fato de que o patrimonialismo ainda era muito forte na administração pública brasileira, sendo muito comum indicações a cargos públicos que geravam controle sobre determinadas áreas, em benefício de grupos de interesse, mantendo-se o nepotismo e o fisiologismo. Cabe ressaltar que esta característica do Estado Brasileiro ainda não foi superada, estando presente no âmbito da gestão federal, estadual e municipal, mantendo-se, entre os grupos de poder, a postura patrimonialista, com o intuito de utilizar o poder público em beneficio destes grupos. (MATIAS-PEREIRA, 2010; SANABIO, SANTOS e DAVID, 2013).

Findada a era Vargas, em 1945, o Brasil vivenciou breve período democrático, interrompido com o Golpe Militar de 1964. Vários são os impactos políticos sociais ocorridos neste período. Com relação à administração pública, assiste-se ao fortalecimento do caráter burocrático, com reforço da perspectiva dos especialistas na formatação das políticas públicas e, consequentemente, o afastamento da participação popular ${ }^{6}$. É um período de grandes planos estratégicos e grandes obras de infraestrutura. Neste momento, o capitalismo mundial apresenta forte crescimento, com grande volume de capitais disponíveis. (MATIASPEREIRA, 2010; SANABIO, SANTOS e DAVID, 2013).

Nesta conjuntura de grandes projetos nacionais com fartura de capital, observa-se um grande crescimento econômico no Brasil, financiado através de um endividamento internacional, sendo este fenômeno conhecido como "Milagre Econômico". O esgotamento desta etapa se dá durante a década de 1970, com a primeira crise do petróleo. Inicia-se um período de recessão nacional que, somado à grande repressão política e social, culmina com o

\footnotetext{
${ }^{6}$ Embora a definição das políticas públicas se desse distante da participação popular, tal fato não impediu uma atuação política da população, que se dava através das Comunidades Eclesiais de Base, redes de solidariedade e Associações de Moradores.
} 
fim do governo militar em 1985. (MATIAS-PEREIRA, 2010; SANABIO, SANTOS e DAVID, 2013).

Em janeiro de 1985 é eleito o primeiro presidente não militar desde 1964. Tal fato marca o início da Nova República, cujo marco principal é a promulgação da Constituição Federal, conhecida como "A Constituição Cidadã", em 1988. Esta Constituição estabelece um novo marco para a Administração Pública brasileira, inaugurando a administração pública gerencial. Como dito anteriormente, o país vive um período de crise financeira, com o Estado não conseguindo atender às demandas políticas sociais de sua população. A introdução de novos referenciais busca um padrão de qualificação da gestão pública de forma a atender estas demandas. (MATIAS-PEREIRA, 2010; SANABIO, SANTOS e DAVID, 2013).

Estas são perspectivas foco das mudanças implementadas na administração pública brasileira após a reforma do Estado iniciada em 1995, por Bresser Pereira, à frente do Ministério da Administração e Reforma do Estado.

\begin{abstract}
A busca por uma gestão pública que contemple uma estrutura de governança adequada, leva ao surgimento de modelos que considerem novas formas de gestão. Algumas estruturas que têm sido propostas e, em alguns casos aplicadas, destacaram aspectos como transparência, accountability e controle, com um padrão que privilegia a simetria de informação e favorece a participação popular (FERREIRA et al., 2010, p.3)
\end{abstract}

Nesta busca pela readequação da administração pública à nova realidade mundial são introduzidos vários princípios da administração privada na administração pública, sendo um ponto central neste processo a adoção dos princípios da governança corporativa na gestão pública, que serão explicitados a seguir.

\title{
5. ADMINISTRAÇÃO PÚBLICA, GOVERNANÇA, ACCOUNTABILITY E CONTROLE SOCIAL
}

Como apresentado anteriormente, ante a crise econômica financeira mundial, muitas foram as propostas apresentadas para se fazer frente ao quadro de vultuosos gastos públicos e diminuição de arrecadação das nações. Com relação à estruturação do Estado, observa-se um conjunto de práticas que buscavam a qualificação das ações com o objetivo de ampliar sua eficiência, efetividade e eficácia. Ocorre um movimento mundial de transição da administração pública burocrática para a administração pública gerencial. É neste contexto da 
nova gestão pública (New Public Manegement) que se inserem os princípios de governança e a accountabillity.

O termo governança provém de um princípio importado da administração privada, Governança Corporativa, cujo princípio fundamental é a transparência, ou seja, uma empresa com boa governança adota ações responsáveis e torna pública todas estas ações, o acesso a seus balanços, práticas, dividendos, dívidas, etc, da forma mais ampla possível. Para isso, a empresa precisa seguir os princípios de equidade, transparência, responsabilidade por prestar contas (accountability), obediência com relação às leis do país (FERREIRA et al, 2010).

A transposição deste conceito e de sua prática na gestão pública instaura um conjunto de novas ações para o gestor público e traz uma profunda mudança de cultura. Assim como na administração privada, a governança na administração pública remete ao arranjo das ações dos agentes públicos nos seus diversos níveis, com o objetivo de melhoria na eficiência e eficácia nas políticas públicas. Ressalta-se que os princípios da democracia devem sempre nortear estas ações, ou seja, a prática da equidade, da transparência, de acountability e da participação social.

Dentro do processo de governança na administração pública, insere-se o princípio da accountability, termo de concepção anglo-saxã, muito discutido na Ciência Política brasileira e que, segundo vários autores (CAMPOS, 1990; PINHO e SACRAMENTO, 2009) ainda sem um termo equivalente na língua portuguesa. No entanto, alguns autores buscam explicar qual seria o significado do termo.

Segundo Fraga (2011); Rocha (2011), accountability seria um conjunto de mecanismos instituídos que determinam a transparência das ações dos gestores públicos, ou seja, cabe ao gestor público criar as condições de acesso às informações da administração pública para que seja possível aos múltiplos atores sociais ${ }^{7}$ realizar a avaliação destas mesmas ações e a determinação das sanções quando estas ações não forem consideradas satisfatórias. Matias-Pereira (2010) apresenta uma leitura muita próxima de Fraga (2011) ao apresentar sua concepção de accountability:

O termo accountability pode ser considerado o conjunto de mecanismos e procedimentos que levam os decisores governamentais a prestarem contas dos resultados de suas ações, garantindo-se maior transparência e a exposição das políticas públicas. Quanto maior a possibilidade de os cidadãos poderem discernir se os governantes estão agindo em função do interesse da coletividade e sancioná-los apropriadamente, mais accountable é um governo.

(MATIAS-PEREIRA, 2010, p. 71).

\footnotetext{
${ }^{7}$ Atores sociais são todos os interessados na implementação de determinada ação do poder público, desta forma podemos considera-los os múltiplos agentes que se fazem presentes no amplo debate social.
} 
Desta forma, pode-se definir sucintamente que accountability seria o conjunto de práticas de controle social sobre o poder público que tem por objetivo gerar um processo de qualificação das ações do poder público. Estas qualificações seriam o resultado do controle e do temor das sanções possíveis decorrentes de uma má gestão pública.

O’Donnel (1998) apresenta a accountability em duas dimensões: horizontal e vertical. O termo horizontal, que se refere ao mesmo patamar, determina os mecanismos de accountability exercidos dentro do próprio poder público, e seriam os controles internos, os Tribunais de Contas, as controladorias estaduais e federal etc. A accountability vertical seria os mecanismos de controle externo ou social, como os movimentos sociais, as consultas públicas, as audiências públicas e os Conselhos de políticas públicas.

Bresser-Pereira (2006) apud Fraga (2011) apresenta cinco tipos de accountability: Responsabilização por controles clássicos; Responsabilização por controle parlamentar; Responsabilização pela introdução da lógica dos resultados; Responsabilização por meio de competição administrada e Responsabilização por meio de controle social. A responsabilização por controle parlamentar trata dos mecanismos de controle entre os poderes, cabendo ao poder legislativo, entre outras atribuições, fiscalizar as ações do poder executivo. A responsabilização pela lógica dos resultados avalia a atuação do gestor público pelos resultados (metas e objetivos estabelecidos) da política pública à qual se vincula. A responsabilização por meio da competição administrada remete à capacidade do poder público, bem como de uma agência reguladora, de exercer controle sobre empresas através de metas estabelecidas para um determinado setor de concessão pública. E a responsabilização por meio do controle social, à capacidade dos movimentos sociais ou grupos organizados de exercerem pressão sobre a formulação, implementação, execução e avaliação das políticas públicas.

\footnotetext{
Essa evolução (...) trouxe consigo novas responsabilidades para a sociedade, que se viu instada a responder por uma dupla obrigação: dos cidadãos, de manter uma estreita vigilância sobre o uso do poder concedido àqueles que foram escolhidos para governá-los; e dos governantes de prestar contas das suas ações aos cidadãos que os escolheram. Daí, um dos problemas mais importantes dos regimes democráticos modernos consiste em desenvolver formas e instrumentos de accountability, isto é, processos de avaliação e responsabilização permanente dos agentes públicos que permitam ao cidadão controlar o exercício do poder concedidos aos seus representantes. (ROCHA, 2011, p. 84)
} 
Pode-se observar que não há possibilidade de existência dos princípios da governança e de accountability em um ambiente que não seja o da democracia. Assim, para a efetividade da governança, é imprescindível o acesso às informações (transparência) sobre as ações do poder público, transparência em relação a contratos, pagamentos, convênios, contratações, folha de pagamento.

A participação para ser efetiva demanda informações precisas e confiáveis que permitam ao cidadão construir um quadro referencial da atuação do governo e, a partir daí, atuar no sentido de exigir que os representantes expliquem as suas ações, mudem sua forma de agir ou mesmo alterem os objetivos das políticas públicas (ROCHA, 2011, p. 85).

O acesso às informações e a capacidade de analisá-las são o que efetivam a accountability e com especial ênfase à possibilidade dos atores envolvidos nesta análise, os atores sociais, conselheiros, cidadãos, imprensa, poderem exercer mecanismos de punição a uma gestão temerária.

Ressalta-se que se trata de uma mudança de referenciais culturais muito significativa, considerando que a cultura cívica nacional se construiu por base em governos populistas e ditatoriais, onde a possibilidade de participação social sempre foi muito limitada e os agentes públicos também se emolduraram desta forma, sem uma cultura de prestação de contas ou controle externo.

\section{A EFETIVIDADE DO CONTROLE SOCIAL NAS POLÍTICAS PÚBLICAS}

Conforme destacado ao longo deste texto, muito se evoluiu em termo da qualidade da administração pública, bem como da perspectiva de maior controle dos agentes públicos por parte da população por meio dos mecanismos de governança. No entanto, também se ressalta que não é suficiente um conjunto de leis para mudar a cultura da população, bem como a cultura dos agentes públicos.

É a prevalência desses traços tradicionais que motiva O’Donnell (1988) a considerar a democracia da América Latina como um tipo particular de democracia e a adjetivá-la como "delegativa", isto é, situação na qual ocorrem eleições livres, mas o vencedor do processo eleitoral está autorizado a governar da maneira que lhe parecer conveniente, não necessitando atuar em conformidade com o prometido durante a campanha eleitoral. Em outras palavras, sacrificando a accountability (PINHO; SACRAMENTO, 2009, p.1361). 
$\mathrm{Na}$ alternância de governos populistas e ditatoriais, a população teve seu direito de participação nas decisões do poder público cerceado, o que acabou por impedir o surgimento de uma cultura política ${ }^{8}$ ou de participação. Roberts (2004) apud Rocha (2011) afirma que a participação é a ação executada pelo cidadão em conjunto com os agentes do poder público visando à definição das ações do segundo na comunidade, ou seja, decisões compartilhadas. Patemam (1992) Sabioni, Ferreira, Braga, Almeida (2016) apresentam o processo de participação como um processo educacional onde a prática participativa qualifica esta participação, ou seja, quanto mais se participa, melhor fica a participação. O Centro Latinoamericano de Administração para o Desenvolvimento ressalta dois fatores fundamentais para a real efetivação da accountability:

(...) a realização do valor político da accountability depende de dois fatores: um deles é o desenvolvimento da capacidade dos cidadãos de agir na definição das metas coletivas de sua sociedade, já que uma população indiferente à política inviabiliza tal processo; o outro é a construção de mecanismos institucionais que garantam o controle público das ações dos governantes ao longo de todo o seu mandato (PINHO; SACRAMENTO, 2009, p.1352-1353).

Pode-se afirmar que, na ausência da participação e de controle social, observa-se que também os agentes públicos não passaram pelo processo de aprendizado em prestar contas de suas ações. Destaca-se neste processo de prestação de contas a transparência das ações do poder público. Denomina-se transparência pública a publicização das informações orçamentárias, de execuções físicas, de execuções financeiras e patrimoniais. Quanto maior for a quantidade e qualidade destas informações apresentadas ao conjunto da população, maior será a transparência de uma administração. Filgueiras (2010) e Pinheiro (2016) ressaltam que o "poder público" pode ter interesse no segredo, pois um conjunto de múltiplos interesses individuais de cada funcionário como: cargos, promoções, benefícios, poderia favorecer a omissão de informações relevantes ao controle social. O interesse individual colocado à frente do interesse coletivo.

Serafim (2008) Sabioni, Ferreira, Braga, Almeida (2016) explicitam a relação entre democracia e transparência. O poder público deve ampliar a transparência, bem como relacionar-se melhor com a questão da avaliação do público. Quanto maior e melhor forem as

\footnotetext{
${ }^{8}$ Cultura política é o conjunto de atitudes, crenças e sentimentos que dão ordem e significado a um processo político, evidenciando as regras e pressupostos que orientam o comportamento de seus atores (KRRUSHNIR ; CARNEIRO,1999 apud PINHO; SACRAMENTO, 2009, p.1360).
} 
informações maior é a capacidade da população em exercer o controle social e exercer mecanismos de punição a uma administração corrupta ou não qualificada.

Nota-se que houve grandes avanços nos processos de transparência, por exemplo, a partir da Lei n. 12.5271/ 2011, chamada Lei de Acesso à Informação, a qual estabeleceu os procedimentos para o acesso às informações relacionadas às ações públicas. No entanto, observa-se um distanciamento do grande público deste conjunto de informações.

Vários pontos são marcantes com relação a pontos fundamentais ao exercício do controle social efetivo. Gohn (2011) e Serafim (2008) apontam que os maiores obstáculos ao pleno exercício do controle social seriam a impossibilidade de acesso às informações realmente relevantes, o atravessamento político partidário nos espaços institucionalizados de controle social, como conselhos de políticas públicas, a linguagem inadequada (muito técnica) dos documentos e dos debates e por fim o descomprometimento do poder público com a participação, de forma objetiva, com relação ao controle social.

Os ocupantes de cargos eletivos no Brasil ainda mantêm padrões de administração pública muito aquém dos princípios de accountability, ou seja, os governantes ainda mantêm uma postura patrimonialista sobre a estrutura do Estado. A distribuição de cargos entre familiares, a utilização de bens públicos em benefício pessoal e outras práticas são ainda muito comuns nos agentes do poder público. PINHO; SACRAMENTO, 2009; PINHEIRO , 2016).

Pode-se afirmar que houve avanços na construção de uma cultura participativa e de accountability, mas a cultura patrimonialista se transforma através de discursos modernos e das práticas arcaicas.

Ser cidadão num regime democrático significa possuir uma série de direitos, entre os quais a prerrogativa de participar da escolha de seus governantes e de influir nas suas decisões. Mas significa, também, uma série de obrigações sociais, entre as quais a de participar daquelas atividades diretamente vinculadas à seleção dos governantes e da vigilância sobre as suas ações (ROCHA, 2011, p. 84 e 85).

Não é necessário entranhar-se muito nas leituras e estudos para que seja possível enumerar algumas dezenas de casos que corroboram esta afirmativa. Sendo assim, considerase fundamental o aprofundamento da democracia com a ampliação dos mecanismos de participação popular de forma a gerar-se um maior capital social ${ }^{9}$.

\footnotetext{
9 Capital Social, termo cunhado por Robert Putnam que remete à capacidade de ligação subjetiva dos cidadãos a determinadas localidades e projetos, o que os leva a uma postura participativa e reivindicativa.
} 


\section{CONSIDERAÇÕES FINAIS}

Para realizar esta discussão, percorreu-se o caminho realizado pela administração pública durante sua trajetória de constituição, observando as principais características em cada período histórico. Nesta transição, observou-se a transformação de um modelo de gestão patrimonialista, fruto do poder real que determinava todos os padrões da gestão pública, bem como quem seriam seus representantes na estrutura de poder, passando a um modelo burocrático que, na busca de estabelecimento de uma nação liberal, buscava a impessoalidade, o método e o padrão como formas de trabalho e execução das ações dos servidores públicos. Observa-se aqui a ascensão da classe burguesa que permanecerá à frente do poder econômico e político em todo o mundo, até os dias atuais.

A transição ao modelo gerencial de administração pública se deu em função de grave crise econômica mundial. Buscou-se dinamizar a capacidade de gestão do poder público, era preciso "fazer mais com menos". Todos estes momentos foram apresentados numa visão mundial e numa visão nacional discutindo seus momentos e formas de implementação. O Brasil, como ocupante de uma posição complementar na estrutura capitalista mundial, recebeu estas modernizações com um certo tempo de atraso e buscou implementa-las contextualizando-as frente à sua realidade como nação.

Tal fato será marcante na organização da administração pública brasileira, pois observam-se traços das três formas de organização da administração pública presentes simultaneamente na gestão pública brasileira: traços patrimonialistas, burocráticos e gerenciais.

Observa-se que uma parte significativa da classe política nacional considera os bens públicos como propriedades pessoais durante seus mandatos; os servidores públicos utilizam da burocracia como meio para impedir o acesso aos cidadãos aos serviços que eles deveriam prestar e uma outra parcela de servidores e população busca mudar este estado de coisa, buscando transpor as barreiras impostas pelos primeiros. A realidade apresenta um país que é rico em discursos modernos de gestão, mas ainda tem práticas muito arcaicas.

Neste trajeto de execução do artigo, realizaram-se leituras de vários artigos de autores diferenciados que nos últimos anos tem se proposto a discutir sobre a administração pública, bem como os mecanismos de controle e prestação de contas do poder público a accountability. A pesquisa, conforme já apresentado em outros momentos neste artigo, foi uma pesquisa qualitativa de cunho teórico, para a qual se utilizou a pesquisa bibliográfica. 
Afirma-se que a implementação dos mecanismos de controle social na administração pública brasileira tem acontecido de forma contínua. A partir da Constituição de 1988, a participação social e o controle social são referenciais de todas as políticas públicas brasileiras e de outras estratégias. A reforma gerencial realizada a partir de 1996 implementa vários mecanismos de governança e de accountability, o que fortalece esta característica participativa da gestão pública nacional e fortalece os mecanismos de controle. No entanto, o fato de se institucionalizar a participação e o controle social, ou seja, de instituí-la através da lei, não significa por si só sua efetivação e desta forma não se observam impactos na qualificação das políticas públicas.

A experiência indica que é possível ter vários mecanismos para se criar uma figura de participação, mas mantendo o controle exercido pelos mesmos grupos tradicionais. Esta constatação é consubstanciada pela observação da dificuldade que o público ou os representantes indicados por eles têm de avaliar os documentos e prestações de contas apresentados pelo poder público, bem como compreender as informações que ali são apresentadas. Observa-se também que o discurso proposto pelos técnicos acaba por ser pouco hermenêutico, impedindo ou desfavorecendo a discussão com os representantes populares.

Uma cultura clientelista patrimonialista como a que se apresenta na realidade brasileira não se altera apenas por força de lei, são necessários mecanismos que propiciem a compreensão das pessoas frente ao papel da democracia e dos direitos sociais. Torna-se fundamental a ampliação da democracia em nosso país, por isso devemos ampliar ao máximo as possibilidades de participação da população brasileira.

É preciso ampliar a cultura de participação, gerar um sentimento de indignação na população com relação à má gestão da coisa pública, bem como um sentimento de poder, este poder representado na capacidade de se mobilizar e exercer mecanismo de controle sobre os agentes públicos. Muito se fala em vontade política para a realização das ações necessárias em favor da maioria da população, mas pode-se afirmar que não existe vontade política, o que existe é mobilização e organização frente a um objetivo social. 


\section{REFERÊNCIAS}

ALMEIDA, Fernanda Maria de. Revista de Administração Pública. Rio de Janeiro 50(3):477-500, maio/jun. 2016

Brasília- DF. Anais do X Congresso Internacional de Humanidades. Disponível em: <http://www.onda.eti.br/revistaintercambio/conteudo/arquivos/1031.doc>. Acesso em: 7 Março 2015.

BRESSER-PEREIRA, L.; GRAU, C. N. (Coord.). Responsabilização na administração pública. São Paulo: CLAD; FUNDAP, 2006.

CAMPOS, Anna Maria. Accountability: quando poderemos traduzi-la para o português? Revista de Administração Pública, Rio de Janeiro, fev./abr. 1990.

COSTIN, Claudia. Administração pública. Rio de Janeiro: Elsevier, 2010.

FERREIRA, Roberto do Nascimento et al. Governança Pública: Transparência, Controle e Accountability Sob a Ótica da Teoria do Agente. In: IV Encontro Nacional de Pesquisadores em Gestão Social. 2010, Lavras, Minas Gerais. Anais... Lavras: ENAPEGS, 2010. p.1-13.

FILGUEIRAS, Fernando. Além da transparência: accountability e política da publicidade. Lua Nova, São Paulo, 84: 353-364, 2011.

FRAGA, Celso da Silva. Accountability e controle social. In: $8^{\circ}$ Congresso de Administração Pública. 2011. Anais do $8^{\circ}$ Congresso de Administração Pública. Lisboa. INA. p.138-150.

LUCHMAN, Lígia Helena Hahn. Democracia Deliberativa: Sociedade Civil, esfera pública e institucionalidade. Cadernos de Pesquisa, $n^{\circ}$. 33, Novembro 2002.

MACIEL, Carlos Alberto Batista. Políticas Públicas e Controle Social: encontros e desencontros da experiência brasileira. In: Anais do X Congresso Internacional de humanidades, 2007,

MATIAS-PEREIRA, José. Curso de administração pública: foco nas instituições e ações governamentais. $3^{\text {a }}$ edição. São Paulo: Atlas, 2010.

O’DONNELL, G. Accountability horizontal e novas poliarquias. Lua Nova, 44, p. 27-53, 1998.

OLIVEIRA, Djalma de Pinho Rebouças de. Administração Pública: Foco na otimização do modelo administrativo. São Paulo: Atlas, 2014.

PALUDO, Augustinho Vicente. Administração pública. $5^{\text {a }}$ ed. rev. atual. e ampl. Rio de Janeiro: Forense; São Paulo: Método. 2016.

PINHEIRO, Douglas Antônio Rocha. A legitimidade do controle social da gestão pública: uma resposta a Herbert Wechsler. Revista de Admistração Pública. Rio de Janeiro 50(5):867-883, set./out. 2016 
PINHO, José Antônio Gomes; SACRAMENTO, Ana Rita Silva. Accountability: já podemos traduzi-la para o português. RAP. Rio de Janeiro 43(6):1343-1368, nov./dez. 2009.

ROCHA. Arlindo Carvalho. Accountability na Administração Pública: Modelos Teóricos e Abordagens Contabilidade. Gestão e Governança - Brasília. v. 14 • n. 2, p. 82-97 , mai/ago 2011.

SABIONI, Marjorie; FERREIRA, Marco Aurélio Marques; BRAGA, Marcelo José; ALMEIDA, Fernanda Maria de. Contextos (in)adequados para o engajamento cidadão no controle social. Rev. Adm. Pública [online]. 2016, vol.50, n.3, pp.477-500.

SANABIO, Marcos Tanure Sanabio; SANTOS, Gilmar José dos Santos; DAVID, Marcus Vinicius (Orgs). Administração pública contemporânea: política, democracia e gestão. Juiz de Fora: Ed. UFJF, 2013.

SERAFIM, Lizandra. Controle Social: que caminhos? São Paulo, 2008. Disponível em: <http://www.polis.org.br/UTILITARIOS/editor2.0/UserFiles/File/Texto\%20Liza.pdf. Acesso em: 08 Março 2017.

WEBER, Max. Economia e sociedade: Fundamentos da sociologia compreensiva. Vol. 1. Brasília: Editora da Universidade de Brasília, 2002. 